\title{
Expression of non-protein-coding antisense RNAs in genomic regions related to autism spectrum disorders
}

Dmitry Velmeshev, Marco Magistri and Mohammad Ali Faghihi*

\begin{abstract}
Background: Autism spectrum disorders (ASD) manifest with neurodevelopmental phenotypes including communicative, social and behavioral impairments that affect as many as 1 in 88 children. The majority of autism cases have no known genetic cause, suggesting complex genetics of the disorder, but a few genes of large effect have been identified.

Methods: In order to identify novel ASD genetic correlates, we investigated non-protein coding RNAs (ncRNAs) which are abundantly transcribed from the human genome, enriched in the brain, and have been implicated in neurodevelopmental disorders. Using an algorithm that we developed, we examined a publicly available transcriptomics database, AceView, to identify the natural antisense transcripts (NATs) that overlap with known autism-related genes. We validated the presence and differential expression of NATs in different brain regions of ASD and control brains using qRT-PCR. Additionally, we investigated the subcellular localization of these transcripts in a neuronal cell line using RNA-sequencing (RNA-seq).
\end{abstract}

Results: We found noncoding antisense RNA transcripts at approximately 40\% of loci previously implicated in ASD. We confirmed the expression of 10 antisense RNAs in different postmortem human brain tissues. The expression of five antisense transcripts was found to be region-specific, suggesting a role for these ncRNAs in the development and function of specific brain regions. Some antisense RNAs overlapping suspected ASD genes exhibited concordant expression relative to their sense protein-coding genes, while other sense-antisense pairs demonstrate a discordant relationship. Interestingly, the antisense RNA corresponding to the SYNGAP1 locus (SYNGAP1-AS) was found to be differentially expressed in brain regions of patients with ASD compared to control individuals. RNA-seq analysis of subcellular compartments from SH-SY5Y human neuroblastoma cells demonstrated that antisense RNAs to ASD candidate genes are predominantly expressed in the nucleoplasmic or chromatin compartments, implying their involvement in nuclear-associated processes.

Conclusions: Our data suggests that NATs are abundantly expressed from ASD-related loci and provide evidence for their roles in target gene regulation, neurodevelopment and autism pathogenesis. This class of RNA should therefore be considered in functional studies aimed at understanding genetic risk factors for ASD.

Keywords: Autism, ASDs, Epigenetics, IncRNAs, NATs, ncRNAs

\footnotetext{
*Correspondence: mfaghihi@med.miami.edu

Department of Psychiatry and Behavioral Sciences and Center for

Therapeutic Innovation, University of Miami Miller School of Medicine, 1501 NW 10th Ave., BRB-407, Miami, FL 33136, USA
} 


\section{Background}

Autism spectrum disorders (ASD) are heterogeneous neurodevelopmental disorders, both in terms of clinical manifestations and genetic risk factors [1]. Disease frequency among siblings of affected children is approximately $2 \%$ to $8 \%$, which is much higher than the prevalence rate of the general population and monozygotic twins have $60 \%$ concordance for classic autism and 92\% for broader autistic phenotypes, indicating strong genetic inheritance as the predominant causative agent [2]. Genetic studies show that ASD can arise from rare, but highly penetrant, mutations and genomic imbalances $[3,4]$ with more than a hundred disease-associated genes and genomic loci having been reported $[5,6]$. Such mutations may contribute to ASD etiology by affecting conventional genes directly or indirectly by altering the function of non-protein coding RNAs (ncRNAs) expressed in the same genomic loci. Recent evidence has implicated such ncRNAs in neurodevelopmental and neurodegenerative disorders including autism [7-15].

Large transcriptomic consortiums such as ENCODE [16] and FANTOM $[17,18]$ have demonstrated that the human genome is pervasively transcribed and that the primary output are ncRNAs. Through diverse mechanisms, these ncRNAs control protein production and function at multiple levels, including epigenetic control of their corresponding or distant loci $[19,20]$, alteration of localization, stability or processing of targets $[20,21]$, or by modulating translational efficiency by binding to the 3' UTR of transcripts, as in the case of microRNAs [22,23]. Natural antisense transcripts (NATs) are a conserved class of long (>200 nt in length) ncRNA molecules that are transcribed from the opposite DNA strand of a sense RNA partner with which they have sequence complementarity $[18,24]$. Such antisense RNAs can exert cis-regulatory functions to increase (concordant) or decrease (discordant) expression levels of their corresponding sense mRNA [21]. The gene regulator functions can also work in trans by affecting genes from distant genomic loci.

Here, we developed an algorithm to mine existing public transcriptomic repositories for the presence of NATs that are produced from ASD candidate genes. We believe that ncRNA information processing systems involving such transcripts represent a critical but under-appreciated dimension of the cell machinery that must be considered in order to identify pathological events and facilitate novel therapeutic development strategies for ASD.

\section{Methods}

\section{Ethics statement}

The University of Miami Institutional Review Board has deemed this study exempt from the full review due to the use of de-identified human post-mortem brain samples, with no possibility to track back the identity of the donors. There is no animal study involved in this paper.

\section{Postmortem brain tissue and RNA extraction}

Tissue samples were provided by the National Institute of Child Health and Development (NICHD) at the University of Maryland. A complete description of the samples is provided in Additional file 1: Table S2.

For RNA extraction $\sim 100 \mathrm{mg}$ of brain tissue was lysed in trizol (Life Technologies), $200 \mu \mathrm{L}$ of chloroform were added and the sample was incubated at room temperature for 10 minutes. The samples were then centrifuged for 20 minutes at $4^{\circ} \mathrm{C}$. The supernatant (aqueous phase) was then transferred to a new tube containing 1.5 volumes of $100 \%$ ethanol. The ethanol/RNA mixture was then loaded onto a RNeasy column (Qiagen) and purified as per the manufacturer's instructions, including on-column DNase treatment. Typical yields from both non-ASD and Autism subjects were about $10-12 \mu \mathrm{g}$ of total RNA from $100 \mathrm{mg}$ of tissue.

\section{Primer design}

Primers were designed using Primer 3 software with the sequences from AceView and synthesized by Integrated DNA Technologies (Additional file 2: Table S3). Primers were designed for a splice junction when possible; when primers were designed for an exon they were designed either for a region of the antisense transcript that does not overlap the sense gene or for a region where the antisense overlaps an intron of the sense transcript (Additional file 3: Figure S1). In these cases, strandspecific quantitative real-time RT-PCR was utilized to avoid amplifying the transcript encoded on the opposite strand of DNA.

\section{Quantitative real time RT-PCR (qRT-PCR)}

For qRT-PCR, total RNA was reverse transcribed using the High-Capacity cDNA Reverse Transcription Kit (Life Technologies). The cDNA was then diluted 1:5 and was used as a template for both SYBR Green (Life Technologies, 4368706) and TaqMan qPCR using the ABI 7900 (Life Technologies). TaqMan probes for human PGK1 from Life Technologies (Hs00943178_g1) were used to measure gene expression of the endogenous control. Three technical replicates were performed for each reaction. No-template controls were included in each reaction and the melting curve was analyzed to assess the specificity of each primer (Additional file 4: Appendix 1). In case the primers were designed for a single exon and did not span a splice junction, appropriate no-RT controls were used to avoid including samples contaminated with DNA. The results of the quantitative real-time RT-PCR were analyzed with SDS 2.3 software from Life Technologies. 


\section{Strand-specific qRT-PCR}

To perform strand-specific measurement of antisense transcript expression, we designed primers for a region of antisense transcript that overlaps with an intron or the promoter of the sense gene. Next, we used one-step RNAto-Ct SYBR Green Kit (Life Technologies, 4389986). We performed reverse transcription (RT) step in a 384-well optical plate using reverse primers to specifically reversetranscribe antisense RNA and to exclude the possibility of measuring the expression of the sense pre-mRNA. Samples were then incubated at $95^{\circ} \mathrm{C}$ for 5 minutes to inactivate the reverse transcriptase enzyme. Forward primers were then added to the reaction and quantitative PCR was performed on the same plate. We included no-RT control and no-template controls for each set of primers to control for non-specific binding.

\section{Statistical analysis}

For all qRT-PCR reactions, three technical replicates were performed. To compare the expression of antisense RNAs across the three brain regions, GraphPad prism software was used to perform ANOVA followed by Tukey post-hoc test. $A p$ value of below 0.05 was considered as statistically significant. The Student's $t$-test was used to compare the expression between the normal brain and ASD.

\section{Cellular fractionation}

SH-SY5Y cells were fractionated using a modified NE-PER Kit (PIERCE) to isolate RNA from the cytosol, nucleoplasm and chromatin. Briefly, the cells were collected and washed twice with PBS. Cell membranes were lysed using a hypotonic buffer and cells were ultra-centrifuged to pellet nuclei, and the cytosol was recovered from the supernatant. Nuclei were further lysed and centrifuged in order to pellet the insoluble chromatin and recover the nuclear extract in the supernatant. The insoluble chromatin pellet was solubilized in PBS with mild sonication. RNA was extracted from each of the three compartments using a combination of two protocols: Trizol LS (Invitrogen) and RNeasy Mini Kit (QIAGEN). Each sample was dissolved in the appropriate amount of Trizol LS ( $1 \mathrm{~mL}$ for $300 \mu \mathrm{L}$ sample) and incubated for $10 \mathrm{~min}$ at room temperature. Chloroform $(200 \mu \mathrm{L}$ for $1 \mathrm{~mL}$ Trizol) was added to the mix and the sample was centrifuged for 20 minutes at $4^{\circ} \mathrm{C}$. The aqueous phase of the supernatant was transferred into a new tube and mixed with 1.5 volumes of absolute ethanol. The sample was then loaded onto the cartridge provided by the QIAGEN kit and on-column DNase treatment was performed as per the manufacturer's protocol. RNA quality was verified using the Agilent Bioanalyzer RNA6000 nano kit.

\section{Library preparation}

RNA samples were prepared for directional RNA sequencing using a modified version of the Illumina sample preparation protocol. Briefly, $1 \mu \mathrm{g}$ of total RNA was processed using Ribo-ZeroTM rRNA Removal Kits to remove ribosomal RNAs. Ribosome-depleted RNA was treated with phosphatase before being treated with T4 polynucleotide kinase (PNK). PNK-treated RNA was then purified with the QIAGEN RNeasy column purification kit and 3' and 5' RNA adapters were ligated to both ends of the RNA in separate reactions. Next, the RNA was reverse transcribed and PCR amplified. PCR products were purified using AMPure beads. RNA sequencing libraries were validated using the Agilent Bioanalyzer High Sensitivity DNA kit and sequenced using the Illumina HiSeq2000 platform at the Genomics sequencing core at the University of Miami. Each sample was run in a single flowcell to increase depth of sequencing.

\section{RNA-seq analysis}

The sequencing reads were pre-processed with a custom Python script to trim library adapters. This allowed the generation of $62,500,000$ reads per sample on average, which provided an acceptable coverage and sequencing depth. The trimmed reads were then aligned to the human transcriptome assembly GRCh37 from ENSEMBL using TopHat version 2.0.4 [25]. TopHat was run with default parameters and Samtools [26] were used to calculate the alignment statistics for each sample. The bam files generated with TopHat were further used as input for Cufflinks [27] to perform $a b$ initio transcriptome assembly. The assembled fragments were then annotated using the Cuffcompare module of Cufflinks and AceView database file as a reference. The fragments that originated from introns and incompletely spliced RNAs were filtered out, and Fragments Per Kilobase of transcript per Million reads Mapped (FPKM) values for fragments transcribed from each locus were added to obtain locus expression.

\section{Results \\ Bioinformatic identification of ASD-related noncoding RNAs}

AceView is a transcriptome database created and supported by the National Center for Biotechnology Information (NCBI) that represents a curated non-redundant collection of RNA transcripts derived from public cDNA collections (mRNAs from GenBank or RefSeq, and single pass cDNA sequences from dbEST and Trace) [28]. AceView also includes information on tissue-specific expression for transcripts and is an excellent source of transcriptomic data for high-throughput genome-wide studies.

We have developed a bioinformatics pipeline to mine the AceView and to perform high-throughput searches of noncoding RNAs in the antisense orientation to genes of interest (Figure 1a). This pipeline uses information on the genomic coordinates of transcripts, their exonic 

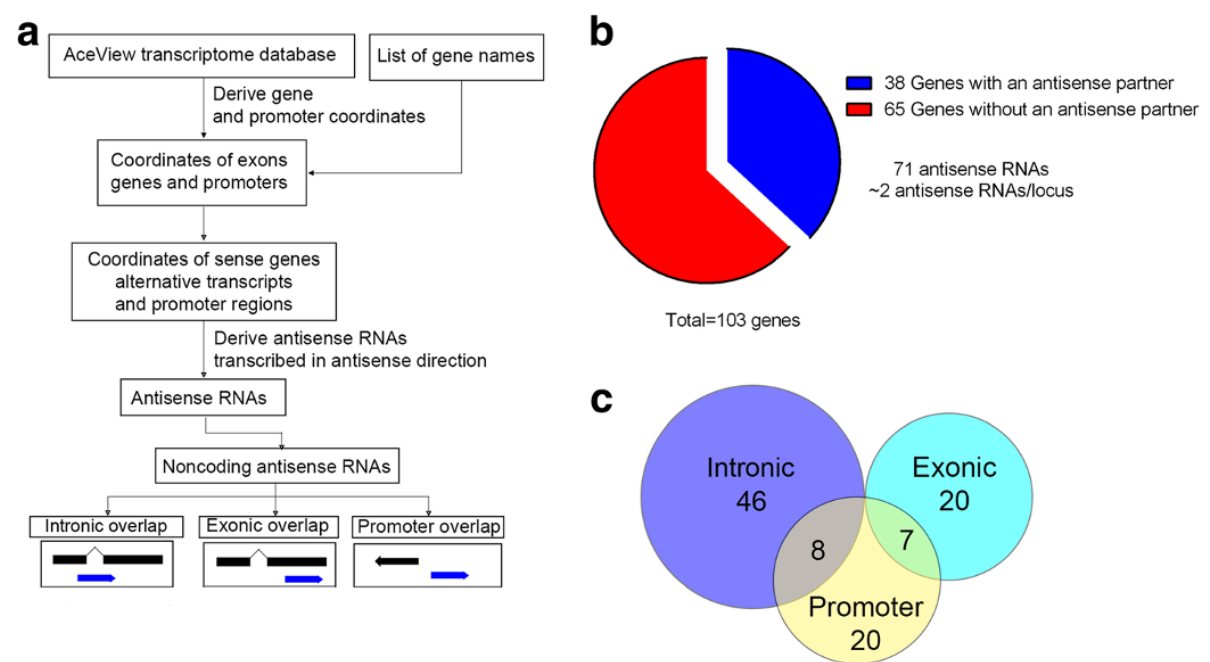

Figure 1 Bioinformatics identification of NATs expressed from ASD-related loci. (a) Bioinformatics pipeline used for the identification of noncoding antisense RNAs. (b) Antisense noncoding RNAs to 103 ASD-related genes derived with our bioinformatics pipeline. Seventy-one noncoding antisense RNAs were identified overlapping 38 of 103 analyzed genes; thus, each sense gene has $\sim$ two antisense RNAs on average. (c) Distribution of noncoding antisense RNAs to ASD-related genes based on the type of sense-antisense overlap. The majority of the antisense RNAs overlaps an intron of the sense gene but do not have an overlap with the mature sense transcript (intronic overlap). Approximately equal numbers of antisense RNAs overlap an exon of the sense transcripts (exonic overlap) or gene promoters (promoter overlap); some of the antisense transcripts with intronic or exonic overlap have mixed classifications and can also overlap the promoter regions of their sense partners.

structure and their coding potential that is contained in the gene transfer format (GTF) files downloaded from the AceView website, to perform a simultaneous search for non-protein-coding antisense RNAs. The program first retrieves, from the AceView database, the exonic coordinates of all alternative transcripts corresponding to a user-provided list of genes. The information of exonic structure of sense transcripts is utilized to obtain AceView transcripts that are in antisense conformation and determine the type of sense-antisense overlap. Next, coding antisense transcripts are filtered out preserving only non-protein-coding transcripts. We utilized this pipeline to investigate the presence of antisense transcripts overlapping 103 genes, mutations of which were causally implicated in ASD [5]. This gene list was selected for our bioinformatics analysis as it was manually annotated by examining existing medical literature and published in a peer-reviewed journal, provided both the scope and confidence in the quality of the analysis [5]. Thus, using this fairly accurate list of genes we were able to identify at least one noncoding antisense RNA partner for 38 of the examined genes (37\%) (Additional file 5: Table S1). Overall, 71 noncoding RNA loci were identified, yielding two antisense partners per sense gene on average (Figure 1b). These antisense RNAs represent three structural classes based on the position of the antisense transcript with respect to the sense gene: intronic overlap, exonic overlap and promoter overlap (Figure 1a and c). Therefore, a significant number of gene loci with
ASD candidate genes have one or more noncoding antisense transcripts that may contribute to ASD pathophysiology and are henceforth referred to as ASD-NATs.

\section{ASD-NATs are expressed in human brain tissues}

Of the 71 identified ASD-NATs, 18 were selected for qRT-PCR validation studies using commercially available RNAs from total brain extract, frontal cortex, and cerebellum. The expression of 12 transcripts was confirmed in at least one brain region or in the total brain extract (Table 1). Notably, the antisense transcript of FOXG1 (FOXG1-AS) was found in the cortex but not in the cerebellum, implying a certain level of region-specificity in the expression of some ASD-NATs. FOXG1 encodes a transcription factor thought to play a role in the development of the cortex [29,30] and mutations in this gene have been reported in a variety of neurodevelopment disorders and higher-order brain function [31].

To expand these studies, we compared expression levels of ASD-NATs across multiple brain regions using a cohort of human postmortem brain samples provided by the NICHD at the University of Maryland. RNA was extracted from three brain regions; the prefrontal cortex (PFC), superior temporal gyrus (STG), and cerebellum (Additional file 1: Table S2). We observed that 9 out of the 10 ASDNATs were detectable in all brain regions, except FOXG1AS, which was detected in all PFC and STG samples but none of the cerebellar samples (Figure 2a and Additional 
Table 1 Antisense RNAs to ASD-related genes expressed in the human brain

\begin{tabular}{llll}
\hline Sense gene name & Antisense gene coordinates & Antisense AceView name & Antisense type \\
\hline FOXP1 & $3: 71630795-71678203,1$ & chyrarbu & exonic; promoter \\
ZNF81 & X:47765952-47764918,-1 & zoyfoy & intronic \\
SYNGAP1 & $6: 33422342-33405140,-1$ & kleefloybu & exonic; promoter \\
CACNA1C & $12: 2781443-2777666,-1$ & kirare & exonic \\
NIPBL & $5: 36876787-36864527,-1$ & LOC646719 & promoter \\
VPS13B & $8: 100026175-100008986,-1$ & speeshor & promoter \\
NHS & $X: 17755214-17658171,-1$ & kiro & exonic \\
DHCR7 & $11: 71159652-71163207,1$ & steymor & intronic; promoter \\
LAMP2 & $X: 119572593-119576511,1$ & werkoy & exonic \\
PTEN & $10: 89631419-89630176,-1$ & kloloy & intronic \\
FOXG1 & $14: 29234525-29194448,-1$ & sachawbu & promoter \\
PQBP1 & $X: 48758712-48758117,-1$ & foyker & exonic; promoter \\
\hline
\end{tabular}

file 6: Figure S3). This finding corroborates our initial analysis using commercial RNA from the frontal cortex, and confirms region-selective expression of FOXG1-AS.

Our data demonstrate that the majority of noncoding antisense RNAs from ASD-related loci are expressed in the human brain and suggest the possibility that certain ASD-NATs may have region-dependent patterns of expression reflecting their biological functions.

\section{ASD-NATs are differentially expressed in human brain regions}

Many ncRNAs are dynamically regulated during differentiation and exhibit tissue- and cell type-specific patterns of expression with proposed functions and mechanisms far more complex than originally anticipated [32-36]. Temporal and spatial expression of many long ncRNAs appears to be crucial for proper CNS development and neurological functioning through the precise regulation of a variety of biological processes [37-39].

Here, we investigated the expression patterns of ASDNATs in the 9 PFC, 9 STG and 7 cerebella of non-ASD young individuals with average age of $15.79 \pm 4.05$ years (Additional file 1: Table S2). Among the 11 selected NATs, we found 6 to be differentially expressed within the examined brain regions. The structure, position in respect to the sense gene and location of the primers for these transcripts is depicted in Figure 3. Three of these transcripts, SYNGAP1-AS, CACNA1C-AS and NIBPL-AS have higher expression levels in the cerebellum as compared to the PFC and STG, while PQBP1-AS is more abundantly expressed in the PFC compared to both the STG and cerebellum and LAMP2-AS was expressed at a higher level in PFC compared to cerebellum (Figure 2a). The region-specific expression of the above antisense transcripts suggests a possible role in the development and function of the PFC, STG and cerebellum. The regionspecificity of these transcripts suggests that NATs are not a product of random spurious transcription and provides a basis for future therapeutic approaches that could be tailored to specific regions of the brain, targeting nonprotein-coding antisense targets instead of proteincoding genes.

\section{ASD-NATs show characteristic patterns of expressions with respect to their sense protein-coding partner} NATs can exert regulatory functions in cis by modulating the expression of neighboring genes $[7,19,21]$. In order to determine if ASD-NATs modulate the expression levels of protein-coding ASD-related genes through cis-regulation, we examined their respective expression levels. We observed discordant patterns of expression for two senseantisense pairs: SYNGAP1/SYNGAP1-AS and PQBP1/ $P Q B P 1-A S$. SYNGAP1 was more highly expressed in the cortex compared to the cerebellum, whereas PQBP1 is more abundant in the cerebellum (Figure 2b). Discordant expression of these exonic sense/antisense pairs suggests possible regulation of the protein-coding gene by its noncoding counterpart, a phenomenon already described for other loci $[15,19,40]$. Two other protein-coding genes, NIPBL and FOXG1, showed a pattern of region-specific expression similar to their promoter-associated antisense partners (Figure 2b). These NATs may have a positive regulatory effect on the sense partner [15], or the senseantisense pairs might be co-regulated [41]. It is noteworthy that these two ASD-NATs overlap the promoter of their protein-coding sense partner, thus potentially sharing the same regulatory elements.

Overall, our data show that ASD-NATs show a regional expression pattern in the brain and further show discordant or concordant expression with regards to their sense partners, suggesting these noncoding antisense transcripts may perform highly specialized regionspecific functions by affecting the expression of their sense partners. 
SYNGAP1 antisense RNA (SYNGAP1-AS) is differentially expressed in ASD brain tissues compared to age-matched controls

The differential expression of ASD-NATs observed across brain regions suggests a tissue-specific function for these RNA transcripts. Thus, we hypothesized that expression of ASD-NATs may be altered in the brain of patients with autism compared to non-ASD cases. To test this hypothesis, we used qRT-PCR to measure the expression of the 10 ASD-NATs that we could detect in the PFC and STG

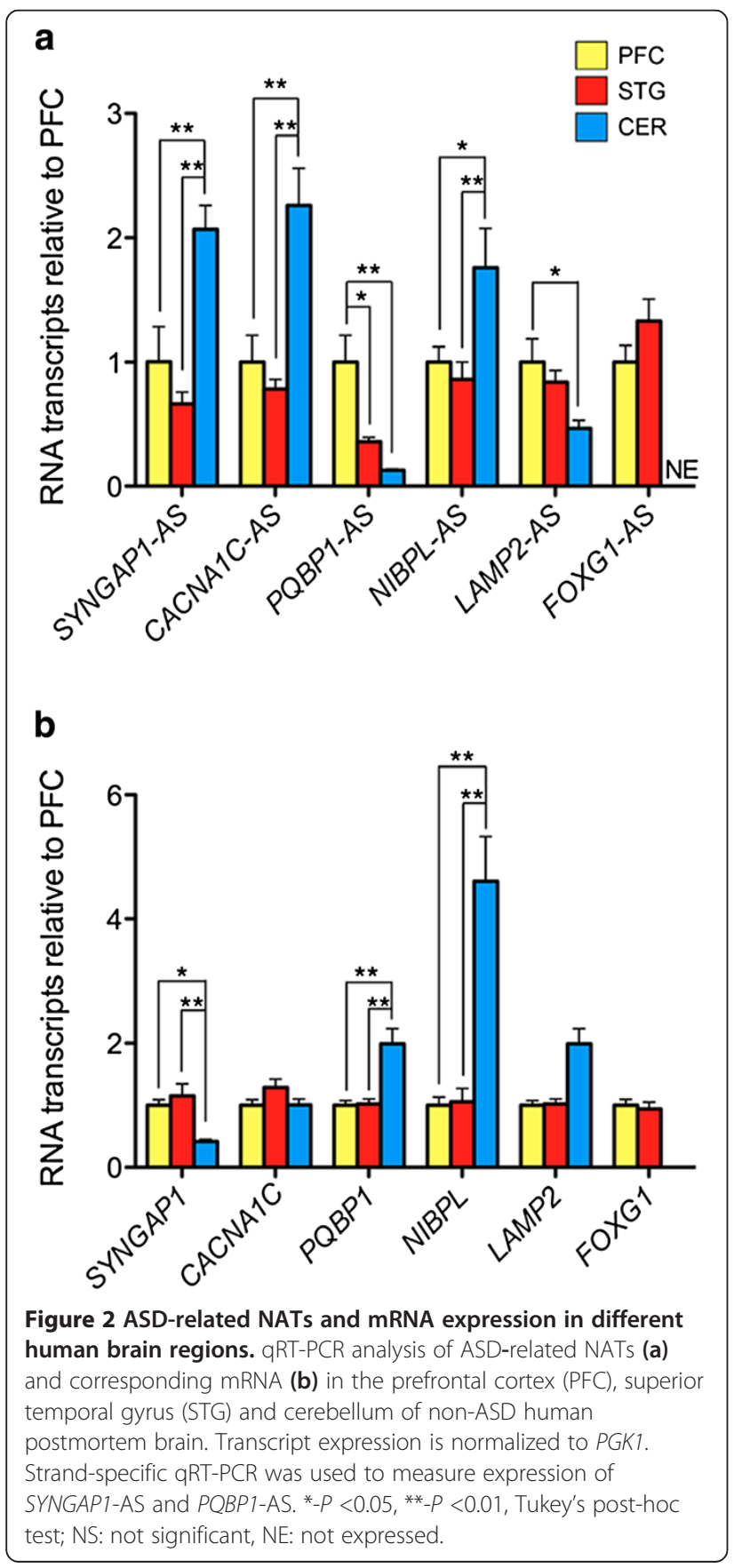

of 18 ( 9 autistic and 9 age-matched individuals) and in the cerebella of 13 (7 autistic and 6 age-matched individuals).

We found SYNGAP1-AS to be significantly upregulated $(p<0.05)$ in the PFC and STG of autistic patients (Figure 4a and b), but not in the cerebellum (Figure 4c). The SYNGAP1 gene codes for Synaptic Ras GTPase activating protein 1 , which is critical for synapse function and is involved in cognition [42]. SYNGAP1 plays a role in brain development as well as higher-order brain function, as mutations in this gene lead to mental retardation [43-45]. Although not statistically significant, three other ASDNATs (FOXG1-AS, VSP13B-AS, NHS-AS) show an appreciable trend of differential expression in ASD (Additional file 7: Figure S4). Additionally, we found that the expression of SYNGAP1-AS negatively correlates with the expression of SYNGAP1 sense gene in the prefrontal cortex of non-ASD individuals (Figure 4d). Our finding that SYNGAP1-AS expression is affected only in the PFC and STG and not in the cerebellum of autistic patients suggests that dysregulation of this non-protein-coding antisense transcript may be cortex-specific, leading to possible impairment of cortical function.

\section{Subcellular localization of ASD-NATs}

Of the proposed functions of NATs [21], regulation of chromatin structure and epigenetic memory has received the most experimental support. Antisense transcripts have been shown to provide a scaffold by which proteins can interact with DNA and histones in a locus specific manner $[19,46]$. Thus, it is not surprising that ncRNAs are predominantly localized to the nucleus or associated with chromatin, while protein-coding RNAs are more abundant in the cytosol [16].

In order to assess the subcellular localization of ASDNATs, we isolated RNA from three cellular fractions (cytoplasm, nucleus, chromatin) of SH-SY5Y neuroblastoma cells and performed RNA sequencing (RNA-seq). FPKM reflecting expression levels of individual loci were used to further compare the expression of antisense RNAs between different compartments (Additional file 8: Dataset S1). We found that three out of 10 ASD-related NATs could be detected in SH-SY5Y cells using RNA-seq: SYNGAP1-AS, VPS13B-AS and NIBPL-AS. All three antisense transcripts were expressed predominantly in the nucleoplasm or chromatin compartments, while little or no expression was observed in the cytoplasm (Figure $5 \mathrm{a}-\mathrm{c}$ ). The pattern of subcellular localization of these ncRNAs is different from that of protein-coding genes such as beta-actin, which is largely localized to the cytoplasm (Figure $5 \mathrm{~d}$ ). The nuclear localization of these NATs offers evidence for the function of these transcripts in nuclear-associated processes and suggests that ASD-NATs might play a role in chromatin modifications or in transcriptional regulation. Overall, these data suggest that ASD-antisense RNAs overlapping genes 


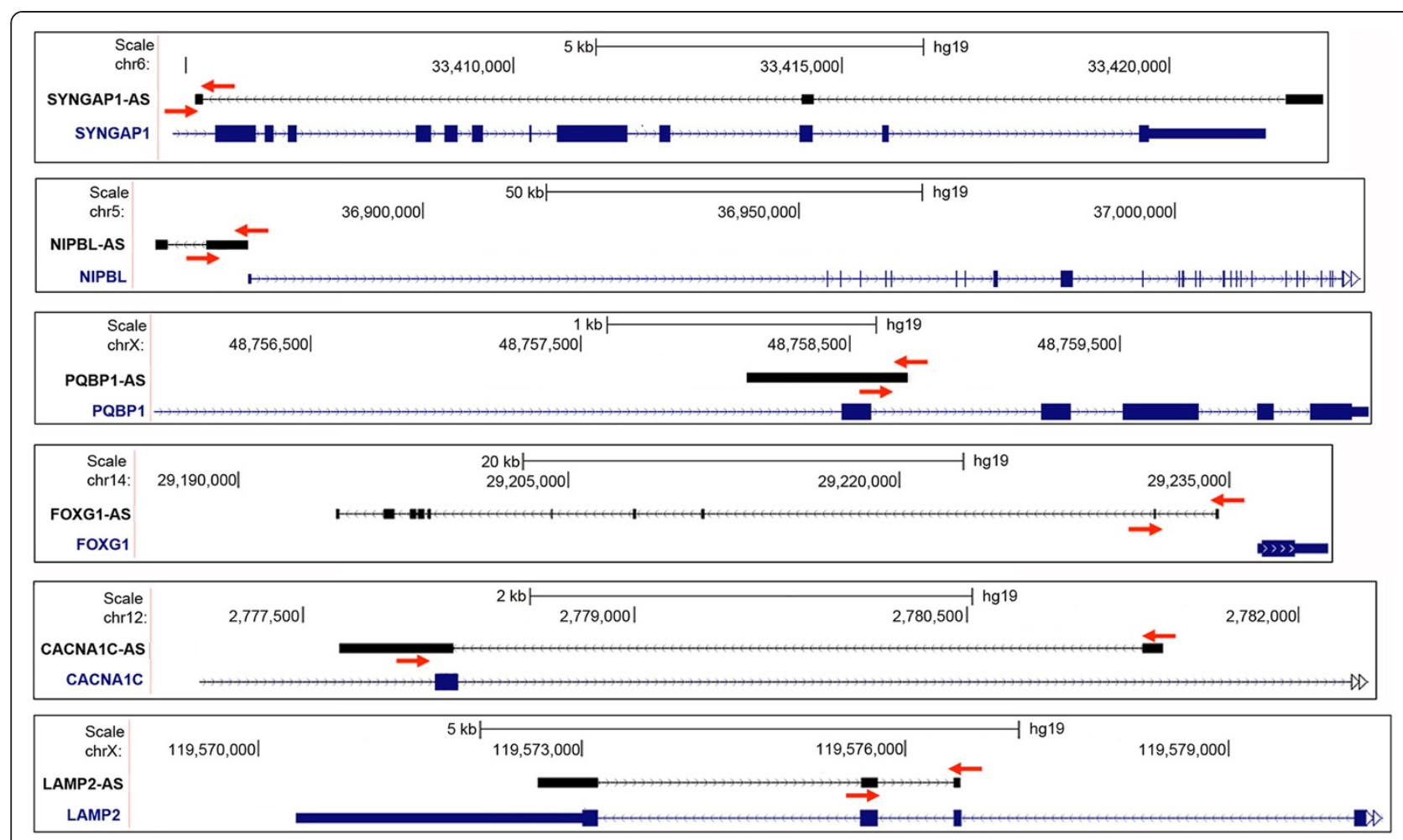

Figure 3 Schematic representation of antisense and sense RNA partners. Diagram showing the genomic location of antisense (in blue) and sense (in black) RNA pairs. The primers used to measure antisense RNAs expression by qRT-PCR are shown as red arrows.

previously implicated in ASD represent functional elements that may regulate brain function and development by regulating transcription of other genes.

\section{Discussion}

Despite overwhelming evidence for the genetic causes of ASD, an exact mode of inheritance has not been elucidated and the wide phenotypic variability of ASD likely reflects the disruption of multiple gene networks and complex regulatory circuits within the genome. Recent data indicate that multiple genomic loci and several rare and highly penetrant gene variants (e.g., NLGN3, NLGN4, SLC9A9, NRXN1, RPL10, SHANK2, SHANK3, CNTNAP2, PTCHD1, and PTEN among others) are involved in ASD $[5,6,47]$. These genes and loci may account for $20-25 \%$ of children with ASD, but none of them can individually explain more than $2 \%$ of the cases [48].

Most eukaryotic genomes are transcribed as ncRNAs of various sizes ranging from 20 nucleotides to over 100 $\mathrm{kb}$ [16]. The number of ncRNAs in eukaryotic genomes increases as a function of developmental complexity $[17,49,50]$. Furthermore, many ncRNAs are expressed in the nervous system where they are thought to mediate fundamental biological functions [51,52]. Natural antisense transcripts have been reported for greater than $70 \%$ of transcriptional units within the human genome [17] and include primate-specific or human-specific [53] as well as other evolutionary conserved transcripts [54]. Aberrant expression of regulatory antisense RNAs might have defined consequences on the expression and/or function of protein-coding transcripts [15] and in some cases on the epigenetic status of the entire genomic loci $[40,55]$. Transcriptomic as well as in vivo studies have revealed the importance of several long ncRNAs in the maturation of neuronal cell subtypes $[38,56,57]$. These recent findings have raised the possibility of a more extensive role for long ncRNAs in regulating gene expression during neuronal differentiation and CNS development. Indeed, it was recently reported that several ncRNAs play functional roles in ASD. For example, a long ncRNA disrupted in schizophrenia 2 (DISC2) is a NAT overlapping the DISC1 gene and has been implicated in schizophrenia, bipolar disorder [58] and autism [59]. A more recent report has indicated the presence of a non-proteincoding antisense RNA corresponding to suspected ASD locus at 5p14.1 [60]. This antisense RNA was shown to be strongly increased in post mortem brain tissue of ASD patients compared to control individuals and mechanistic studies suggested its role in regulating the level of the MOESIN protein. Moreover, mutations in an X-chromosome gene PTCHD1 (Patched Domain Containing 1) were reported in several families with ASD and intellectual disability. Interestingly, deletion of 5 -flanking region of the gene containing a non-coding 

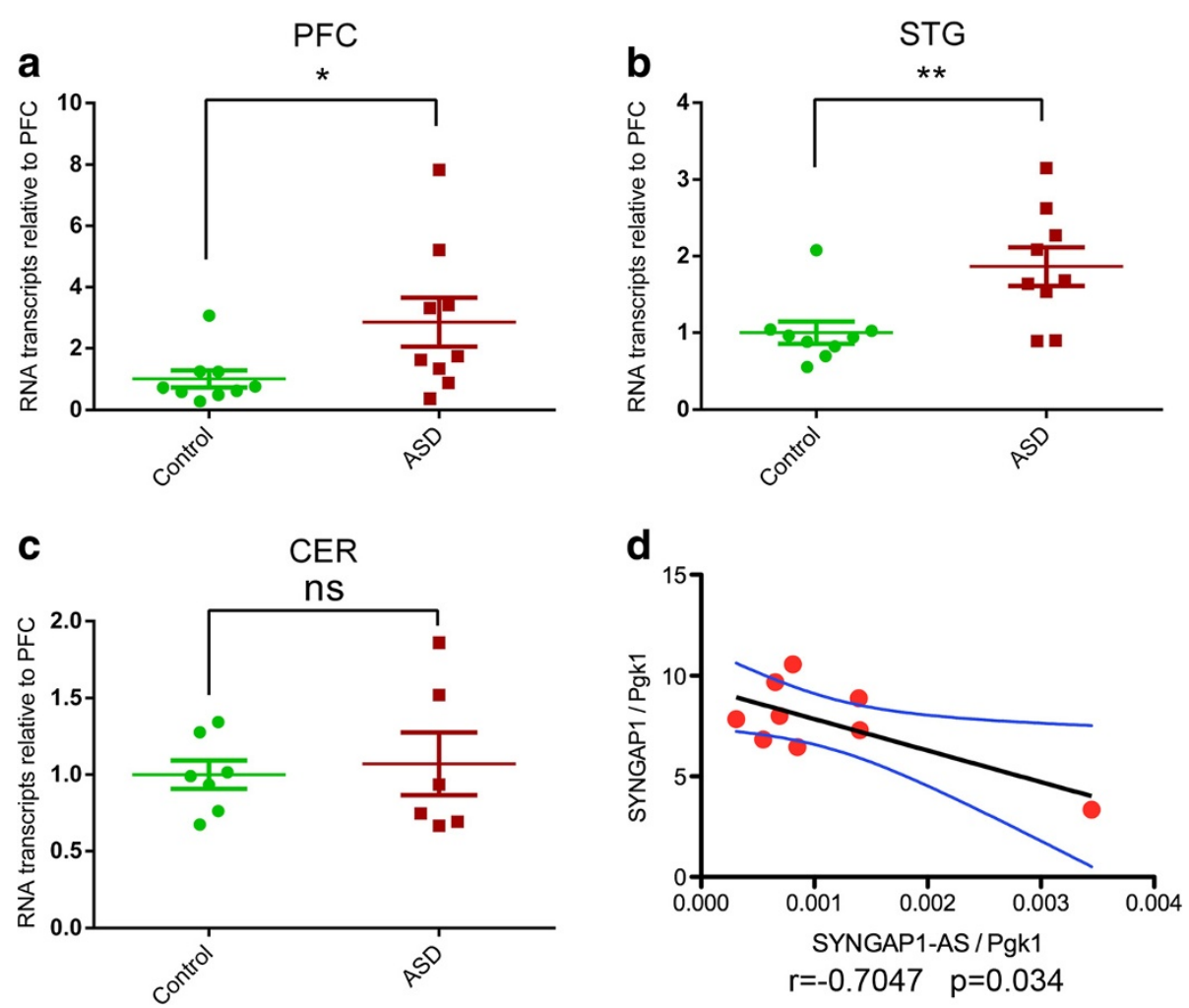

Figure 4 Differential expression of SYNGAP1-AS in the postmortem brain of patients affected by ASD compared to age-matched controls. Strand-specific qRT-PCR analysis of SYNGAP1-AS expression in: (a) Prefrontal cortex (PFC, $n=9$ ), (b) Superior temporal gyrus (STG, $n=9)$ and (c) Cerebellum (CER, $n=7$ ) of ASD patients and age-matched non-ASD individuals. ${ }^{*} P<0.05$, ${ }^{*} P<0.01$, Student's $t$-test. (d) Linear regression plot demonstrating negative correlation of SYNGAP1-AS with SYNGAP1 gene expression in the prefrontal cortex of control individuals. $R=-0.7047, p<0.05$, Pearson Correlation. SYNGAP1-AS expression is normalized to PGK1.

RNA were detected in several males with ASD while not present in controls [61]. Non-protein-coding antisense transcripts are reported in the Fragile X Mental Retardation gene (FMR1) locus. Fragile X syndrome (FXS) is the leading genetic cause of autism and intellectual disability among boys [62]. Although FXS is considered a monogenic disorder, there is evidence that supports an alternative model in which other ncRNAs contribute to FXS pathogenesis and to the observed phenotypic variations among patients $[7,63]$. We previously reported a ncRNA transcribed from the FMR1 locus, FMR4, that is a $2.4 \mathrm{~kb}$ long, primate-specific transcript residing upstream of FMR1 and which may have an anti-apoptotic function [7]. Therefore, the abundance of RNA produced by transcriptional events from nearly every region of the genome combined with the enrichment of ncRNA transcripts in the central nervous system make regulatory RNAs a prime target for mechanistic studies of neurodevelopmental disorders.

In the current study, we explored and validated the expression of ncRNAs in several reported ASD-related genomic loci utilizing bioinformatics and molecular biology approaches. Our bioinformatics pipeline allowed us to identify 71 noncoding antisense RNAs that overlap 38 of 103 genes previously implicated in ASD. These findings indicate that a large proportion of genomic loci implicated in ASD have a complex structure with transcription arising from both the plus and minus strands of DNA. Antisense transcripts can exert regulatory roles on gene expression in cis and trans and can be affected by mutations. Knockdown or blockade of endogenous antisense transcripts can have multiple outcomes, with the corresponding sense transcript concentration showing either an increase (discordant regulation) or a decrease (concordant regulation). It has been proposed that discordant de-repression of sense transcript expression, resulting in upregulation of sense RNA expression, can be achieved by removal or steric blockade of many but not all antisense transcripts. Here, we noticed that two exonic antisense RNAs, SYNGAP1-AS and PQBP1-AS, have tissue expression patterns that are discordant to that of their protein-coding partners, whereas two other promoter-associated antisense RNAs, NIBPL-AS and FOXG1-AS, have concordant tissue expression patterns with their sense genes. These findings suggest a possible functional regulation exerted by these antisense 

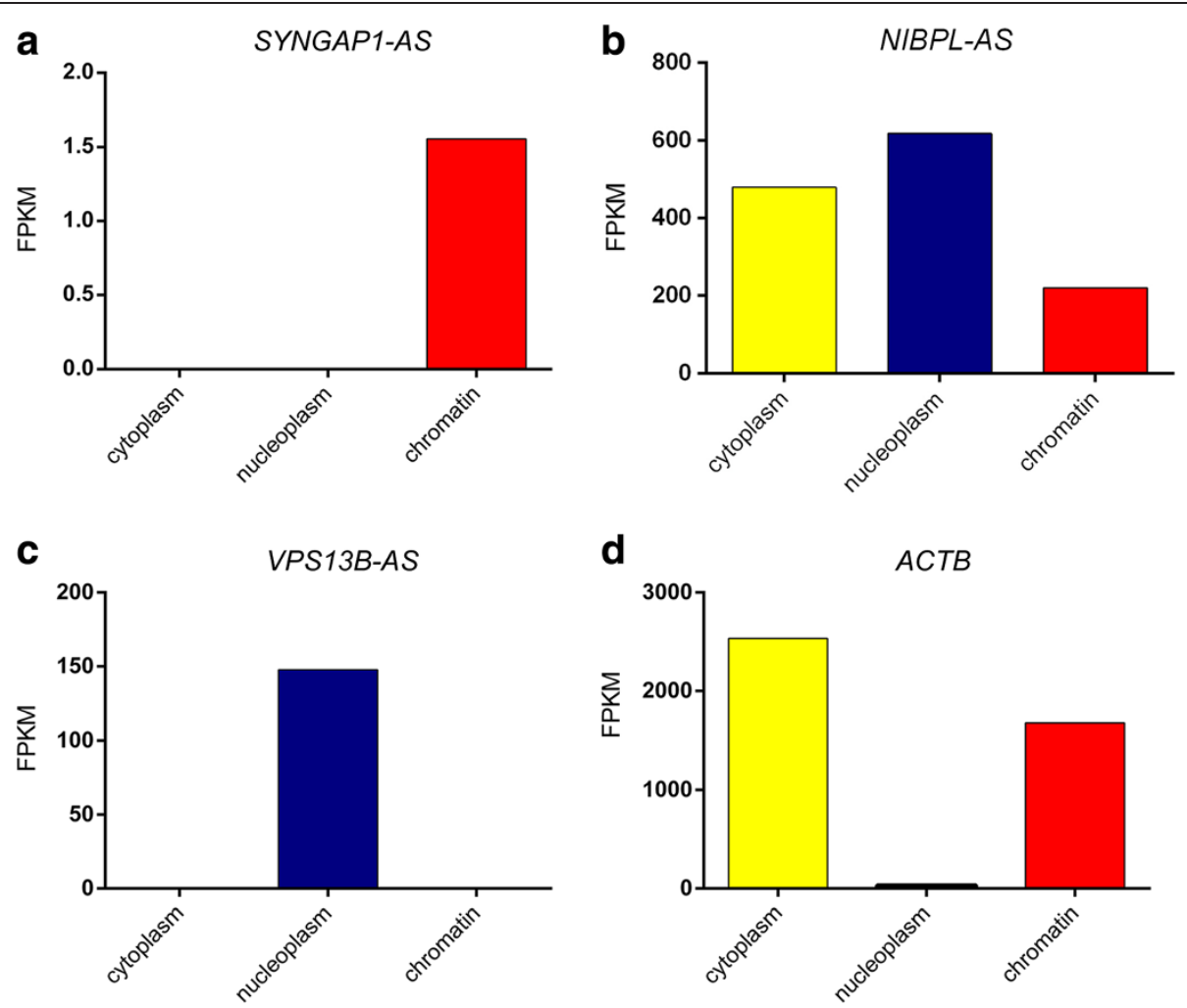

Figure 5 Subcellular localization of antisense transcripts overlapping ASD-related genes. RNAseq analysis of RNA extracted from the cytoplasm, nucleoplasm and chromatin of SH-SY5Y cells. Expression of SYNGAP1-AS (a), NIBPL-AS (b), VPS13B-AS (c), and $\beta$-actin (ACTB) (d) is shown as fragments per kilobase of transcript per million reads mapped (FPKM).

RNAs on their sense counterparts, a phenomenon already described for a subset of sense-antisense pairs [21]. Discordant pairs might interfere with transcription initiation from opposite strand, alter epigenetic structure of or may form double-stranded RNAs. Concordant pairs may potentially share the same regulatory elements, alter stability of sense mRNA or the sense-antisense transcripts are coregulated as recently described for the majority of divergently transcribed long ncRNA/mRNA gene pairs, expressed during embryonic stem cell differentiation [41]. Thus, the presence of these transcripts in several ASD candidate genes suggests complex genomic structure of these loci and warrants functional studies that include both protein-coding genes and regulatory long noncoding antisense transcripts.

We demonstrated that 12 of the 18 randomly selected antisense RNAs overlapping ASD-NATs are expressed in the human brain where they can have specific regional expression, suggesting a possible region-specific function of these RNAs. Differential expression analysis of NATs in the PFC, STG and cerebellum revealed a significant increase in SYNGAP1-AS expression in the PFC and STG of autistic patients compared to control individuals. We also observed a statistically significant negative correlation of SYNGAP1-AS and SYNGAP1 expression in the PFC of non-ASD individuals and a similar trend in the PFC of ASD patients. These data, together with the observed discordant regulation of SYNGAP1-AS and SYNGAP1 mRNA, suggest a possible scenario in which upregulation of antisense RNAs lead to the dysregulation of the protein-coding gene expression.

Many noncoding RNAs function at the chromatin level, acting as scaffolds for the recruitment of functionally related epigenetic enzymes to specific loci [35,64-66]. The expression of these ncRNAs is usually restricted at the nuclear and chromatin level where they exert their function. RNA sequencing analysis of RNA expression in the cytoplasm, nucleoplasm and chromatin of the SH-SY5Y neuroblastoma cell line showed that some ASD-NATs have clear localization in the nucleoplasm or chromatin. The peculiar subcellular localization of these antisense RNAs implies that they may have functional roles in the nucleus and additionally supports the functionality of these ncRNAs in the cell. Among the chromatinassociated antisense RNAs, we found SYNGAP1-AS, providing additional support to the hypothesis that this NAT might have a regulatory function on its sense mRNA partner by mediating the epigenetic modifications of the regulatory elements controlling SYNGAP1 expression. 


\section{Conclusions}

The data presented here provide strong evidence that the molecular network underlying ASD pathology is far more complex than anticipated and may involve dysregulation of ncRNAs. These regulatory elements, which are mostly ignored from current ASD genetics and functional studies, must be taken into account in order to obtain a more holistic view of the interplay of factors that lead to the disease state. We initiated a comprehensive genomic study of ASD that is not dependent solely on protein coding genes, and we demonstrate the expression of NATs in ASDrelated genomic loci. Abundant transcriptions of regulatory ncRNAs in ASD-related genomic regions indicate that, in addition to conventional protein coding genes, disruption of RNA regulatory elements may contribute to the pathogenesis of ASD. Identification of disease specific RNAs [15], as well as novel technologies that enable targeting of these regulatory RNA molecules [40], adds a new dimension to current efforts investigating novel therapeutic targets for ASD.

\section{Additional files}

Additional file 1: Table S2. Patients informations.

Additional file 2: Table S3. Primer sequences for $\mathrm{QRT}$ T-PCR studies.

Additional file 3: Figure S1. Schematic representation of Antisense and Sense RNA partners. Diagram showing the genomic location of Antisense (in blue) and Sense (in black) RNA partners. The primers used to measure antisense RNAs expression by qRT-PCR are shown as red arrows.

Additional file 4: Former appendix1. Melting temperatures.

Additional file 5: Table S1. Antisense RNAs to ASD-related genes.

Additional file 6: Figure S3. ASD-related NATs expression in different human brain regions. QRT-PCR analysis of ASD-related NATs in the prefrontal cortex (PFC), superior temporal gyrus (STG) and cerebellum of non-ASD human postmortem brain samples. Transcripts expression is normalized to PGK1. Strand-specific GRT-PCR was used to measure expression of ZNF81-AS and NHS-AS.

Additional file 7: Figure S4. Expression of FOXG1-AS, VPS13B-AS and NHS-AS in the non-ASD brain and in the brain of patients affected by ASD. qRT-PCR analysis of antisense RNAs expression in the non-ASD brain and brain affected by ASD pathology. (a) Expression of FOXG1-AS in the prefrontal cortex (PFC), (b) Expression of VPS13B-AS in the PFC and (c) Strand-specific qPCR analysis of NHS-AS in the superior temporal gyrus (STG). Antisense RNA expression is normalized to PGK1. $P$ value Student's t-test.

Additional file 8: Dataset S1. Gene expression in the cytoplasm, nucleoplasm and chromatin of SH-SY5Y cells based on RNA-seq.

\section{Abbreviations}

ADI-R: Autism diagnostic interview revised; ASD: Autism spectrum disorders; FPKM: Fragments per kilobase of transcript per million reads mapped; NATs: Natural antisense transcripts; ncRNAs: Non-protein-coding RNAs.

\section{Competing interests}

The authors declare that they have no competing interests.

\section{Authors' contributions}

DV developed bioinformatics pipeline, performed data mining, GRT-PCR, RNA-seq analysis, statistical analysis, prepared figures and drafted the manuscript. MM processed clinical samples, performed RNA extraction, helped in coordination of the project and drafted the manuscript. MAF conceived of the study, helped in its design and coordination, drafted the manuscript and performed RNA-sequencing. All authors read and approved the final manuscript

\section{Acknowledgements}

The Margaret Q. Landenberger Foundation generously supported this work. Funding from the Swiss National Science Foundation supported Dr. Marco Magistri. We are thankful to Dr. Zane Zeier as well as to Roya Pedram-Fatemi and Veronica Peschansky for careful reading of the manuscript. The funders had no role in study design, data collection and analysis, decision to publish, or preparation of the manuscript.

Received: 23 April 2013 Accepted: 6 August 2013

Published: 4 September 2013

\section{References}

1. Mefford HC, Batshaw ML, Hoffman EP: Genomics, intellectual disability, and autism. N Engl J Med 2012, 366:733-743.

2. Muhle R, Trentacoste SV, Rapin I: The genetics of autism. Pediatrics 2004 113:e472-e486.

3. Anney R, Klei L, Pinto D, Almeida J, Bacchelli E, Baird G, Bolshakova N, Bolte S, Bolton PF, Bourgeron T, Brennan S, Brian J, Casey J, Conroy J, Correia C, Corsello C, Crawford EL, de Jonge M, Delorme R, Duketis E, Duque F, Estes A, Farrar P, Fernandez BA, Folstein SE, Fombonne E, Gilbert J, Gillberg C, Glessner JT, Green A, et al: Individual common variants exert weak effects on the risk for autism spectrum disorderspi. Hum Mol Genet 2012, 21:4781-4792.

4. Neale BM, Kou Y, Liu L, Ma'ayan A, Samocha KE, Sabo A, Lin CF, Stevens C, Wang LS, Makarov V, Polak P, Yoon S, Maguire J, Crawford EL, Campbell NG, Geller ET, Valladares O, Schafer C, Liu H, Zhao T, Cai G, Lihm J, Dannenfelser R, Jabado O, Peralta Z, Nagaswamy U, Muzny D, Reid JG, Newsham I, Wu Y, et al: Patterns and rates of exonic de novo mutations in autism spectrum disorders. Nature 2012, 485:242-245.

5. Betancur C: Etiological heterogeneity in autism spectrum disorders: more than 100 genetic and genomic disorders and still counting. Brain Res 2011, 1380:42-77.

6. Miles JH: Autism spectrum disorders--a genetics review. Genet Med 2011, 13:278-294.

7. Khalil AM, Faghihi MA, Modarresi F, Brothers SP, Wahlestedt C: A novel RNA transcript with antiapoptotic function is silenced in fragile $\mathrm{x}$ syndrome. PLOS ONE 2008, 3:e1486.

8. Faghihi MA, Zhang M, Huang J, Modarresi F, Van der Brug MP, Nalls MA, Cookson MR, St-Laurent G 3rd, Wahlestedt C: Evidence for natural antisense transcript-mediated inhibition of microRNA function. Genome Biol 2010, 11(5):R56.

9. Scheele C, Petrovic N, Faghihi MA, Lassmann T, Fredriksson K, Rooyackers O, Wahlestedt C, Good L, Timmons JA: The human PINK1 locus is regulated in vivo by a non-coding natural antisense RNA during modulation of mitochondrial function. BMC Genomics 2007, 8:74

10. Pastori $C$, Wahlestedt $C$ : Involvement of long noncoding RNAs in diseases affecting the central nervous system. RNA Biol 2012, 9:860-870.

11. Mercer TR, Dinger ME, Mariani J, Kosik KS, Mehler MF, Mattick JS: Noncoding RNAs in Long-Term Memory Formation. Neuroscientist 2008, 14:434-445.

12. Pollard KS, Salama SR, Lambert N, Lambot MA, Coppens S, Pedersen JS, Katzman S, King B, Onodera C, Siepel A, Kern AD, Dehay C, Igel H, Ares M Jr, Vanderhaeghen P, Haussler D: An RNA gene expressed during cortical development evolved rapidly in humans. Nature 2006, 443:167-172.

13. Mehler MF, Mattick JS: Non-coding RNAs in the nervous system. J Physiol 2006, 575:333-341.

14. Qureshi IA, Mattick JS, Mehler MF: Long non-coding RNAs in nervous system function and disease. Brain Res 2010, 1338:20-35.

15. Faghihi MA, Modarresi F, Khalil AM, Wood DE, Sahagan BG, Morgan TE, Finch CE, St Laurent G 3rd, Kenny PJ, Wahlestedt C: Expression of a noncoding RNA is elevated in Alzheimer's disease and drives rapid feedforward regulation of beta-secretase. Nat Med 2008, 14:723-730.

16. Djebali S, Davis CA, Merkel A, Dobin A, Lassmann T, Mortazavi A, Tanzer A Lagarde J, Lin W, Schlesinger F, Xue C, Marinov GK, Khatun J, Williams BA, Zaleski C, Rozowsky J, Röder M, Kokocinski F, Abdelhamid RF, Alioto T, Antoshechkin I, Baer MT, Bar NS, Batut P, Bell K, Bell I, Chakrabortty S, Chen 
X, Chrast J, Curado J, et al: Landscape of transcription in human cells. Nature 2012, 489:101-108.

17. Carninci P, Kasukawa T, Katayama S, Gough J, Frith MC, Maeda N, Oyama R, Ravasi T, Lenhard B, Wells C, Kodzius R, Shimokawa K, Bajic VB, Brenner SE, Batalov S, Forrest AR, Zavolan M, Davis MJ, Wilming LG, Aidinis V, Allen JE, Ambesi-Impiombato A, Apweiler R, Aturaliya RN, Bailey TL, Bansal M, Baxter $\mathrm{L}$, Beisel KW, Bersano T, Bono H, et al: The transcriptional landscape of the mammalian genome. Science 2005, 309:1559-1563.

18. Katayama S, Tomaru Y, Kasukawa T, Waki K, Nakanishi M, Nakamura M, Nishida H, Yap CC, Suzuki M, Kawai J, Kodzius R, Shimokawa K, Bajic VB, Brenner SE, Batalov S, Forrest AR, Zavolan M, Davis MJ, Wilming LG, Aidinis V, Allen JE, Ambesi-Impiombato A, Apweiler R, Aturaliya RN, Bailey TL, Bansal M, Baxter L, Beisel KW, Bersano T, Bono $H$, et al: Antisense transcription in the mammalian transcriptome. Science 2005, 309:1564-1566.

19. Magistri M, Faghihi MA, St Laurent G 3rd, Wahlestedt C: Regulation of chromatin structure by long noncoding RNAs: focus on natural antisense transcripts. Trends Genet 2012, 28(8):389-396.

20. Wang KC, Chang HY: Molecular mechanisms of long noncoding RNAs. Mol Cell 2011, 43:904-914.

21. Faghihi MA, Wahlestedt C: Regulatory roles of natural antisense transcripts. Nat Rev Mol Cell Biol 2009, 10:637-643.

22. Carthew RW, Sontheimer EJ: Origins and Mechanisms of miRNAs and siRNAs. Cell 2009, 136:642-655.

23. Malone CD, Hannon GJ: Small RNAs as guardians of the genome. Cell 2009, 136:656-668

24. Chen J, Sun M, Hurst LD, Carmichael GG, Rowley JD: Genome-wide analysis of coordinate expression and evolution of human cis-encoded senseantisense transcripts. Trends Genet 2005, 21:326-329.

25. Trapnell C, Pachter L, Salzberg SL: TopHat: discovering splice junctions with RNA-Seq. Bioinformatics 2009, 25:1105-1111.

26. Li H, Handsaker B, Wysoker A, Fennell T, Ruan J, Homer N, Marth G, Abecasis G, Durbin R: The Sequence Alignment/Map format and SAMtools. Bioinformatics 2009, 25:2078-2079.

27. Trapnell C, Williams BA, Pertea G, Mortazavi A, Kwan G, van Baren MJ, Salzberg SL, Wold BJ, Pachter L: Transcript assembly and quantification by RNA-Seq reveals unannotated transcripts and isoform switching during cell differentiation. Nat Biotechnol 2010, 28:511-515.

28. Thierry-Mieg D, Thierry-Mieg J: AceView: a comprehensive cDNA-supported gene and transcripts annotation. Genome Biol 2006, 7(Suppl 1):S12.1-14

29. Danesin C, Houart C: A Fox stops the Wnt: implications for forebrain development and diseases. Curr Opin Genet Dev 2012, 4:323-330.

30. Miyoshi G, Fishell G: Dynamic FoxG1 expression coordinates the integration of multipolar pyramidal neuron precursors into the cortical plate. Neuron 2012, 74:1045-1058.

31. Kortum F, Das S, Flindt M, Morris-Rosendahl DJ, Stefanova I, Goldstein A, Horn D, Klopocki E, Kluger G, Martin P, Rauch A, Roumer A, Saitta S, Walsh LE, Wieczorek D, Uyanik G, Kutsche K, Dobyns WB: The core FOXG1 syndrome phenotype consists of postnatal microcephaly, severe mental retardation, absent language, dyskinesia, and corpus callosum hypogenesis. J Med Genet 2011, 48:396-406.

32. Kretz M, Siprashvili Z, Chu C, Webster DE, Zehnder A, Qu K, Lee CS, Flockhart RJ, Groff AF, Chow J, Johnston D, Kim GE, Spitale RC, Flynn RA, Zheng GX, Aiver S, Raj A, Rinn JL, Chang HY, Khavari PA: Control of somatic tissue differentiation by the long non-coding RNA TINCR. Nature 2013, 493:231-235.

33. Sun L, Goff LA, Trapnell C, Alexander R, Lo KA, Hacisuleyman E, Sauvageau M, Tazon-Vega B, Kelley DR, Hendrickson DG, Yuan B, Kellis M, Lodish HF, Rinn JL: Long noncoding RNAs regulate adipogenesis. Proc Natl Acad Sci USA 2013, 110:3387-3392.

34. Kretz M, Webster DE, Flockhart RJ, Lee CS, Zehnder A, Lopez-Pajares V, Qu K, Zheng GX, Chow J, Kim GE, Rinn JL, Chang HY, Siprashvili Z, Khavari PA: Suppression of progenitor differentiation requires the long noncoding RNA ANCR. Genes Dev 2012, 26:338-343.

35. Guttman M, Donaghey J, Carey BW, Garber M, Grenier JK, Munson G, Young G, Lucas AB, Ach R, Bruhn L, Yang X, Amit I, Meissner A, Regev A, Rinn JL, Root DE, Lander ES: lincRNAs act in the circuitry controlling pluripotency and differentiation. Nature 2011, 477:295-300.

36. Klattenhoff CA, Scheuermann JC, Surface LE, Bradley RK, Fields PA, Steinhauser ML, Ding H, Butty VL, Torrey L, Haas S, Abo R, Tabebordbar M, Lee RT, Burge CB, Boyer LA: Braveheart, a long noncoding RNA required for cardiovascular lineage commitment. Cell 2013, 152:570-583.
37. Barry G, Mattick JS: The role of regulatory RNA in cognitive evolution. Trends Cogn Sci 2012, 16:497-503.

38. Mercer TR, Qureshi IA, Gokhan S, Dinger ME, Li G, Mattick JS, Mehler MF: Long noncoding RNAs in neuronal-glial fate specification and oligodendrocyte lineage maturation. BMC Neurosci 2010, 11:14.

39. Mercer TR, Dinger ME, Sunkin SM, Mehler MF, Mattick JS: Specific expression of long noncoding RNAs in the mouse brain. Proc Natl Acad Sci USA 2008, 105:716-721.

40. Modarresi F, Faghihi MA, Lopez-Toledano MA, Fatemi RP, Magistri M, Brothers SP, van der Brug MP, Wahlestedt C: Inhibition of natural antisense transcripts in vivo results in gene-specific transcriptional upregulation. Nat Biotechnol 2012, 30:453-459.

41. Sigova AA, Mullen AC, Molinie B, Gupta S, Orlando DA, Guenther MG, Almada AE, Lin C, Sharp PA, Giallourakis CC, Young RA: Divergent transcription of long noncoding RNA/mRNA gene pairs in embryonic stem cells. Proc Natl Acad Sci USA 2013, 110:2876-2881.

42. Kim JH, Liao D, Lau LF, Huganir RL: SynGAP: a synaptic RasGAP that associates with the PSD-95/SAP90 protein family. Neuron 1998, 20:683-691.

43. Hamdan FF, Gauthier J, Spiegelman D, Noreau A, Yang Y, Pellerin S, Dobrzeniecka S, Cote M, Perreau-Linck E, Carmant L, D'Anjou G, Fombonne E, Addington AM, Rapoport JL, Delisi LE, Krebs MO, Mouaffak F, Joober R, Mottron L, Drapeau P, Marineau C, Lafrenière RG, Lacaille JC, Rouleau GA, Michaud JL, Synapse to Disease Group: Mutations in SYNGAP1 in autosomal nonsyndromic mental retardation. N Engl J Med 2009, 360:599-605.

44. Pinto D, Pagnamenta AT, Klei L, Anney R, Merico D, Regan R, Conroy J, Magalhaes TR, Correia C, Abrahams BS, Almeida J, Bacchelli E, Bader GD, Bailey AJ, Baird G, Battaglia A, Berney T, Bolshakova N, Bölte S, Bolton PF, Bourgeron T, Brennan S, Brian J, Bryson SE, Carson AR, Casallo G, Casey J, Chung BH, Cochrane L, Corsello C, et al: Functional impact of global rare copy number variation in autism spectrum disorders. Nature 2010, 466:368-372.

45. Clement JP, Aceti M, Creson TK, Ozkan ED, Shi Y, Reish NJ, Almonte AG, Miller BH, Wiltgen BJ, Miller CA, Xu X, Rumbaugh G: Pathogenic SYNGAP1 mutations impair cognitive development by disrupting maturation of dendritic spine synapses. Cell 2012, 151:709-723.

46. Rinn JL, Chang HY: Genome regulation by long noncoding RNAs. Annu Rev Biochem 2012, 81:145-166.

47. O'Roak BJ, Vives L, Fu W, Egertson JD, Stanaway IB, Phelps IG, Carvill G Kumar A, Lee C, Ankenman K, Munson J, Hiatt JB, Turner EH, Levy R, O'Day DR, Krumm N, Coe BP, Martin BK, Borenstein E, Nickerson DA, Mefford HC, Doherty D, Akey JM, Bernier R, Eichler EE, Shendure J: Multiplex targeted sequencing identifies recurrently mutated genes in autism spectrum disorders. Science 2012, 6114:1619-1622.

48. Voineagu I: Gene expression studies in autism: moving from the genome to the transcriptome and beyond. Neurobiol Dis 2012, 45(1):69-75.

49. Liu G, Mattick JS, Taft RJ: A meta-analysis of the genomic and transcriptomic composition of complex life. Cell Cycle 2013, 13:2061-2072.

50. Kapranov P, Cheng J, Dike S, Nix DA, Duttagupta R, Willingham AT, Stadler PF, Hertel J, Hackermuller J, Hofacker IL, Bell I, Cheung E, Drenkow J, Dumais E, Patel S, Helt G, Ganesh M, Ghosh S, Piccolboni A, Sementchenko V, Tammana $\mathrm{H}$, Gingeras TR: RNA maps reveal new RNA classes and a possible function for pervasive transcription. Science 2007, 316:1484-1488.

51. St Laurent G 3rd, Wahlestedt C: Noncoding RNAs: couplers of analog and digital information in nervous system function? Trends Neurosci 2007, 30:612-621.

52. Ng SY, Bogu GK, Soh BS, Stanton LW: The Long Noncoding RNA RMST Interacts with SOX2 to regulate Neurogenesis. Mol Cell 2013, 3:349-359.

53. Bush EC, Lahn BT: A genome-wide screen for noncoding elements important in primate evolution. BMC Evol Biol 2008, 8:17

54. Engstrom PG, Suzuki H, Ninomiya N, Akalin A, Sessa L, Lavorgna G, Brozzi A, Luzi L, Tan SL, Yang L, Kunarso G, Ng EL, Batalov S, Wahlestedt C, Kai C, Kawai J, Carninci P, Hayashizaki Y, Wells C, Bajic VB, Orlando V, Reid JF, Lenhard B, Lipovich L: Complex Loci in human and mouse genomes. PLoS Genet 2006, 2:e47.

55. Yap KL, Li S, Munoz-Cabello AM, Raguz S, Zeng L, Mujtaba S, Gil J, Walsh MJ, Zhou MM: Molecular interplay of the noncoding RNA ANRIL and methylated histone $\mathrm{H} 3$ lysine 27 by polycomb CBX7 in transcriptional silencing of INK4a. Mol Cell 2010, 38:662-674.

56. Bond AM, Vangompel MJ, Sametsky EA, Clark MF, Savage JC, Disterhoft JF, Kohtz JD: Balanced gene regulation by an embryonic brain ncRNA is critical for adult hippocampal GABA circuitry. Nat Neurosci 2009, 12:1020-1027. 
57. Qureshi IA, Mehler MF: Emerging roles of non-coding RNAs in brain evolution, development, plasticity and disease. Nat Rev Neurosci 2012, 13:528-541.

58. Millar JK, James R, Brandon NJ, Thomson PA: DISC1 and DISC2: discovering and dissecting molecular mechanisms underlying psychiatric illness. Ann Med 2004, 36:367-378.

59. Williams JM, Beck TF, Pearson DM, Proud MB, Cheung SW, Scott DA: A $1 q 42$ deletion involving DISC1, DISC2, and TSNAX in an autism spectrum disorder. Am J Med Genet A 2009, 149A:1758-1762.

60. Kerin T, Ramanathan A, Rivas K, Grepo N, Coetzee GA, Campbell DB: A noncoding RNA antisense to moesin at 5p14.1 in autism. Sci Trans/ Med 2012, 4:128ra140.

61. Noor A, Whibley A, Marshall CR, Gianakopoulos PJ, Piton A, Carson AR, OrlicMilacic M, Lionel AC, Sato D, Pinto D, Drmic I, Noakes C, Senman L, Zhang X, Mo R, Gauthier J, Crosbie J, Pagnamenta AT, Munson J, Estes AM, Fiebig A, Franke A, Schreiber S, Stewart AF, Roberts R, McPherson R, Guter SJ, Cook EH Jr, Dawson G, Schellenberg GD, et al: Disruption at the PTCHD1 Locus on Xp22.11 in Autism spectrum disorder and intellectual disability. Sci Transl Med 2010, 2:3001267.

62. De Rubeis $\mathrm{S}$, Bagni $\mathrm{C}$ : Regulation of molecular pathways in the Fragile $\mathrm{X}$ Syndrome: insights into Autism Spectrum Disorders. J Neurodev Disord 2011, 3:257-269.

63. Ladd PD, Smith LE, Rabaia NA, Moore JM, Georges SA, Hansen RS, Hagerman RJ, Tassone F, Tapscott SJ, Filippova GN: An antisense transcript spanning the CGG repeat region of FMR1 is upregulated in premutation carriers but silenced in full mutation individuals. Hum Mol Genet 2007, 16:3174-3187.

64. Gupta RA, Shah N, Wang KC, Kim J, Horlings HM, Wong DJ, Tsai MC, Hung T, Argani P, Rinn JL, Wang Y, Brzoska P, Kong B, Li R, West RB, van de Vijver MJ, Sukumar S, Chang HY: Long non-coding RNA HOTAIR reprograms chromatin state to promote cancer metastasis. Nature 2010 464:1071-1076.

65. Nagano T, Mitchell JA, Sanz LA, Pauler FM, Ferguson-Smith AC, Feil R, Fraser $P$ : The Air noncoding RNA epigenetically silences transcription by targeting G9a to chromatin. Science 2008, 322:1717-1720.

66. Wang KC, Yang YW, Liu B, Sanyal A, Corces-Zimmerman R, Chen Y, Lajoie BR, Protacio A, Flynn RA, Gupta RA, Wysocka J, Lei M, Dekker J, Helms JA, Chang HY: A long noncoding RNA maintains active chromatin to coordinate homeotic gene expression. Nature 2011, 472:120-124.

doi:10.1186/2040-2392-4-32

Cite this article as: Velmeshev et al:: Expression of non-protein-coding antisense RNAs in genomic regions related to autism spectrum disorders. Molecular Autism 2013 4:32.

\section{Submit your next manuscript to BioMed Central and take full advantage of:}

- Convenient online submission

- Thorough peer review

- No space constraints or color figure charges

- Immediate publication on acceptance

- Inclusion in PubMed, CAS, Scopus and Google Scholar

- Research which is freely available for redistribution 